\title{
Food- and Drug-Reinforced Responding: Effects of DITA and $d$-Amphetamine*
}

\author{
DAVID A. DOWNS and JAMES H. WOODS
}

Departments of Pharmacology and Psychology, University of Michigan, Ann Arbor, Michigan

Received December 10, 1974

\begin{abstract}
Intravenous pretreatment with DITA $(0.1-1.0 \mathrm{mg}$ $\mathrm{kg}$ ) decreased the rate of food-reinforced lever pressing in rhesus monkeys. Response rate decreases were dose-dependent but showed the development of tolerance. Self-administration of DITA was initiated and maintained in each of three monkeys when 30 lever presses were required to produce each injection. Maximal response rate during periods of drug availability was maintained by $0.03 \mathrm{mg} / \mathrm{kg} /$ injection while higher and lower doses $(0.01$ and $0.10 \mathrm{mg} / \mathrm{kg} /$ injection $)$ maintained lower response rates. Response rate in periods of food availability immediately preceding drug periods was relatively
\end{abstract}

constant across sessions; response rate in periods of food availability immediately following drug periods, however, decreased with increasing amounts of drug self-administered. Replication of initial self-administration doses produced results comparable to original determinations in contrast to the tolerance observed with DITA effects upon food-reinforced responding. DITA was about 3 times less potent than $d$-amphetamine in maintaining response rates in drug periods and in decreasing the rate of subsequent food-reinforced responding.

Key words: Drug Self-Administration - DITA - d-Amphetamine - Food Reinforcement - Fixed-Ratio - Lever-Press Rhesus Monkeys.

\section{Introduction}

DITA [3',4'-dichloro-2-(2-imidazolin-2-yl-thio)-, acetophenone hydrobromide] is a new anorexigenic compound which does not contain a phenylethylamine moiety (Fig. 1). Moreover, when compared to $d$-amphetamine, DITA reduces eating at doses which are smaller relative to doses which cause death. On the other hand, the drug appears to be similar to $d$-amphetamine in increasing spontaneous locomotor activity in mice (Abdallah and White, 1974). Because many amphetamine-like drugs function as reinforcers in rhesus monkeys and are abused by humans (Woods and Tessel, 1974), it was important to determine whether or not DITA would also be self-administered. We examined DITA self-administration using a procedure in which each period of drug availability was preceded and followed by periods of food-reinforced responding.

\section{Methods}

Subjects. Four experimentally naive male rhesus monkeys (Macaca mulatta), weighing from $3.5-5.0 \mathrm{~kg}$, were used in

* This research was supported in part by USPHS Grant DA00154 and by a gift from Dow Chemical Company. DITA was provided by Dow Chemical U.S.A., Midland, Michigan.

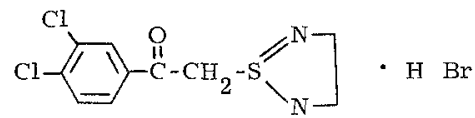

Fig. 1. Structural formula of DITA $\left(3^{\prime}, 4^{\prime}\right.$-dichloro-2-(2-imidazolin-2-yl-thio)-, acetophenone hydrobromide)

the experiment. Each monkey was surgically prepared with a silicone rubber catheter (inside diameter: $0.079 \mathrm{~cm}$; outside diameter: $0.24 \mathrm{~cm}$; Rodhelm Reiss, Inc.) in either the right or left internal jugular vein or the right or left femoral vein. The distal end of the catheter was passed under the skin and exited from the midscapular area. A leather vest was fitted to each monkey to protect the catheter. Animals were fed Purina monkey biscuits with $608.3 \mathrm{~g} /$ ton isoniazid added by the manufacturer to prevent tuberculosis. Diets were supplemented with fresh fruit occasionally. Water was freely available in home cages. Following recovery from surgery, the animals were food-deprived to $80 \%$ of their free-feeding weights and maintained at that level throughout the experiment.

Apparatus. During experimental sessions, the monkeys were seated in restraint chairs enclosed within sound-attenuating cubicles. Each cubicle contained a response lever (Lehigh Valley Electronics, mode1 121-07) and various colored stimulus lights. Catheters were connected to a motor-driven syringe (Sage Instruments, Inc., model 249-2) located outside the cubicle. White noise was continuously present within the cubicle to mask extraneous sounds. 
Procedure. Every lever press (response) in the presence of a green light initially resulted in the delivery of a $0.3 \mathrm{~g}$ bananaflavored food pellet (P. J. Noyes Company, Lancaster, N.H.). The response requirement was increased gradually to thirty lever presses (FR30). When FR30 performance was established, each food pellet delivery was followed by illumination of a white light for $5 \mathrm{sec}$. Each response in the presence of the white light postponed the onset of the green light for $5 \mathrm{sec}(\mathrm{DRO} 5)$. The DRO interval was gradually increased across sessions to $30 \mathrm{sec}$ (DRO 30). When performance was established under the chain DRO 30 FR30 schedule of reinforcement, a 1-min limited hold (LH1) was instituted; that is, if a monkey failed to press the lever thirty times within 1 min whenever the green light was illuminated, a food pellet was forfeited and subtracted from the total number of pellets available. Forty food pellets, whether obtained or forfeited, constituted Food Period I.

Immediately after Food Period I ended, a 1-hr Drug Period was in effect. Forty injections were available; each injection was obtained by pressing the lever 30 times. Each injection consisted of $0.5 \mathrm{ml}$ of solution injected over $15 \mathrm{sec}$. Following each injection, there was a 30 -sec time-out during which responses had no consequences. Instances of drug availability, injections, and time-outs respectively were signalled by blue, red, and blackout stimulus-light conditions. The Drug Period lasted for 60 min independently of whether all 40 injections were obtained. When all 40 injections were obtained before the end of the hour, the remaining portion of the hour was spent in blackout. Immediately after the Drug Period, a second Food Period was presented; conditions in Food Period II were identical to Food Period I.

The actual length of each session depended on the monkey's performance in the two Food Periods since the Drug Period always lasted $1 \mathrm{hr}$. When a monkey obtained all forty food pellets in each of the two Food Periods, the total session lasted for about $1 \mathrm{hr}$ and $50 \mathrm{~min}$. It was possible, however, for a single Food Period to last as long as $60 \mathrm{~min}$ if a monkey failed to obtain any food pellets; thus a total session could last as long as 3 hrs. Sessions were conducted 5 days/week.

Intravenous Pretreatment with DITA. Presession intravenous injections of DITA $(0.1-1.0 \mathrm{mg} / \mathrm{kg})$ in distilled water were examined to determine a behaviorally active dose range. Injections were given through the catheter immediately prior to the start of Food Period I. A pretreatment was tested every fourth experimental session. Saline injections were tested on the second session following each DITA pretreatment. Doses were varied unsystematically.

During this initial phase of the study, only saline was available for self-administration during the Drug Period of each session.

Self-Administration of DITA. After determining the rate of saline self-administration, DITA was made available. Each dose ( $\mathrm{mg} / \mathrm{kg} /$ injection) was presented for 5 to 22 consecutive sessions, depending upon the judged stability of performance (no consistent upward or downward trend in response rates across sessions). After testing doses of $0.01,0.03$, and $0.1 \mathrm{mg} / \mathrm{kg} /$ injection, the dose at which self-administration first was initiated in each animal was replicated. After replication of the initial self-administration doses, intravenous pretreatment with $1.0 \mathrm{mg} / \mathrm{kg}$ was repeated. The purpose of replication of the $1.0 \mathrm{mg} / \mathrm{kg}$ pretreatment was to determine if the history of DITA self-administration produced tolerance to the response rate-decreasing effects of that drug on foodreinforced performance. Three monkeys were used in this portion of the experiment $(628,723,724)$ For purposes of comparison, some doses of $d$-amphetamine sulfate (dissolved in $0.9 \%$ saline) were tested for self-administration in 1 monkey (628) previously exposed to DITA and in 1 monkey (750) previously exposed only to saline. All drug doses refer to the salts.

\section{Results}

Intravenous Pretreatment. Rate of food-reinforced responding decreased in Food Period I as the pretreatment dose of DITA was increased (Fig. 2; closed symbols). Thus, presession injection of $0.1 \mathrm{mg} / \mathrm{kg}$ DITA slightly reduced the response rate in Food Period I, but this depression of performance did not extend into Food Period II. Pretreatment with $0.3 \mathrm{mg} / \mathrm{kg}$ caused greater suppression in Food Period I, but again the suppression did not substantially affect responding in Food Period II. Pretreatment with $1.0 \mathrm{mg} / \mathrm{kg}$ nearly completely suppressed responding in Food Period I; in this case, however, response suppression also extended into Food Period II. The second and third determinations (Fig. 2; open symbols) at the same doses consistently showed reduced effects at the higher doses, despite the fact that DITA pretreatments were given only once every 4 sessions. A fourth determination at $1.0 \mathrm{mg} / \mathrm{kg}$ was obtained after the selfadministration phase and will be described below.

The normally low control mean rates of responding during DRO 30 components (0.062 responses/sec in Food Period I, 0.067 responses/sec in Food Period II) were affected in essentially the same way as the foodreinforced performance. That is, the low response rates were only further decreased as DITA pretreatment dose increased.

Immediately after sessions in which pretreatments were given, monkeys accepted regular rations of food into their cheek pouches, although food-reinforced lever pressing may have been partially or completely suppressed during the experimental session just completed. However, no attempt was made to determine the amount of food actually swallowed from the cheek pouches or the time course of consumption of the food once it was put into the cheek pouches. Food pellets obtained during Food Periods always were consumed before the end of the session.

DITA Self-Administration. When only saline was available in the Drug Period, the rate of responding was very low in that portion of the session (Fig. 3; closed symbols); this resulted in an average delivery of 10 injections of saline per session (Fig. 3; open symbols). The first dose of DITA tested for selfadministration was $0.01 \mathrm{mg} / \mathrm{kg} /$ injection. Within the first session, 2 of the 3 monkeys $(628,723)$ showed increases in response rate compared to the previous 


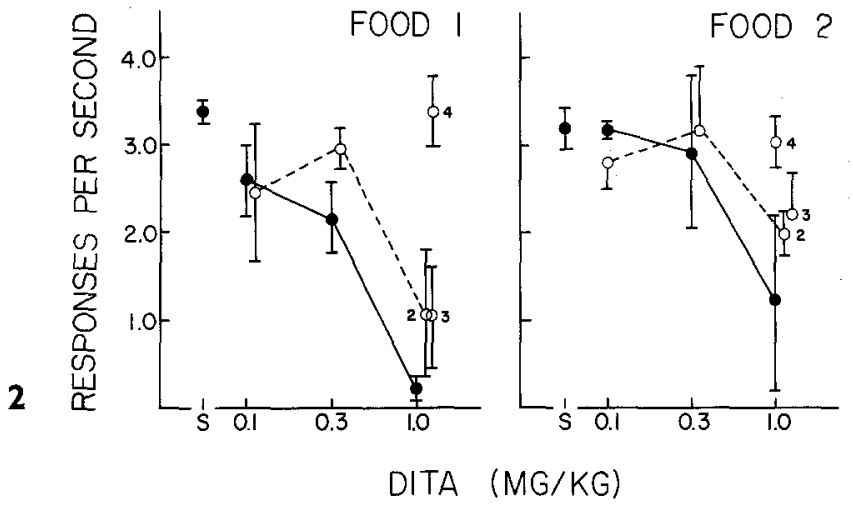

Fig. 2. Effects of DITA pretreatment or saline on response rates maintained by food under the FR30 component of a chain DRO $30 \mathrm{sec}$ FR30 schedule. Each point represents the mean of a single observation in each of 3 monkeys (628, $723,724)$. Closed circles represent the first determination at each dose; open circles connected by broken lines represent second determinations. Third and fourth determinations at $1.0 \mathrm{mg} / \mathrm{kg}$ are indicated by numerals beside data points. A $1 \mathrm{hr}$ period intervened between Food Period I and Food Period II. Vertical lines signify \pm 1 S.E.

Fig. 3. FR30 response rate (closed symbols) as a function of DITA (circles) or $d$-amphetamine (squares) dose $(\mathrm{mg} / \mathrm{kg} /$ injection). The upper graph shows Food Period I; the center graph shows the Drug Period; the lower graph shows Food Period II. Open symbols represent Drug Period injections/ session according to the scale on the right ordinate of the center graph. Each point represents the mean of the last 5 sessions at each dose. Vertical lines show \pm 1 S.E. The points at $S$ (saline) were determined before DITA selfadministration in monkeys 628,723 , and 724 . DITA was tested in 628,723 , and 724 . Amphetamine was tested in 628 and 750

Fig. 4. FR30 response rate in Drug Period as a function of DITA dose ( $\mathrm{mg} / \mathrm{kg} /$ injection) or saline in individual monkeys. Each point represents the mean of the last 5 sessions at each dose. Open circles show replications. Vertical lines indicate the range about each mean

saline control level. Response rate and number of injections continued to increase over sessions in those 2 monkeys. In monkey 724, however, response rate and number of injections remained the same as for saline over 5 sessions. The dose for 724 was then raised to $0.03 \mathrm{mg} / \mathrm{kg} /$ injection, whereupon selfadministration was initiated and maintained. Mean response rate in the Drug Period first increased and then decreased as DITA dose was increased (Fig. 3; closed symbols). In the individual monkeys, maximal response rates in the Drug Period were maintained at $0.03 \mathrm{mg} / \mathrm{kg} /$ injection in 723 and 724 , while maximal
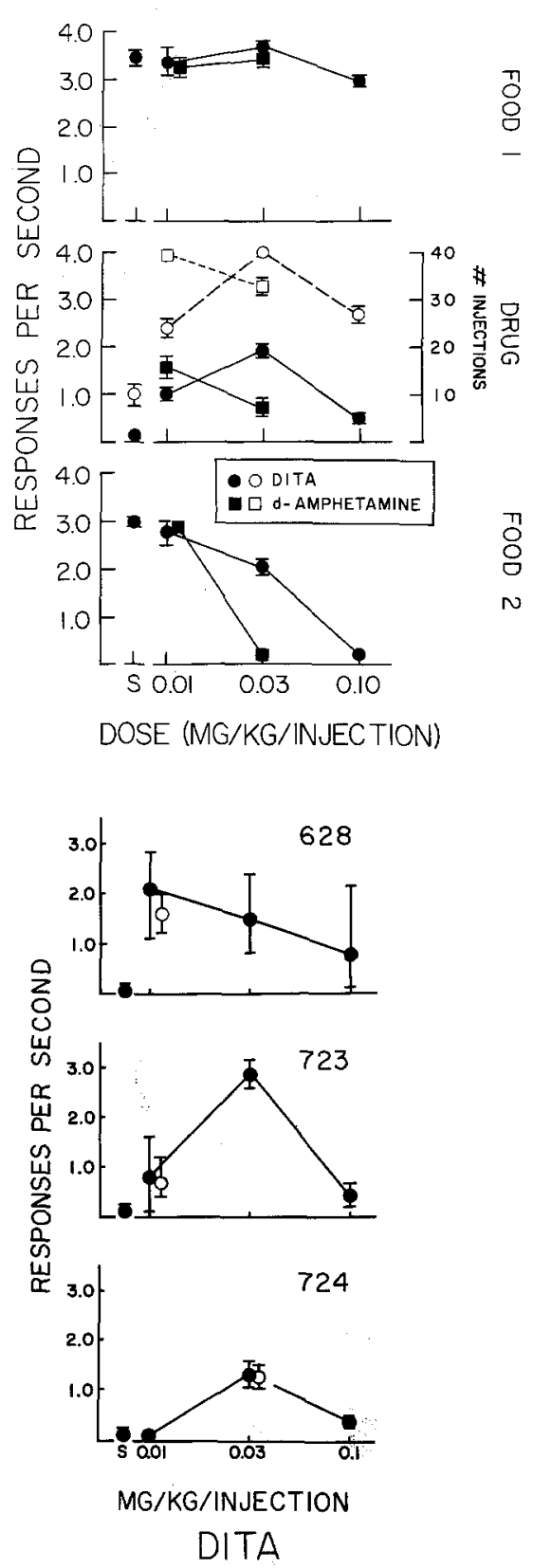

4 rates in 628 were obtained at the lowest dose tested, $0.01 \mathrm{mg} / \mathrm{kg} /$ injection (Fig. 4).

Regardless of the self-administration dose, response rate in Food Period I remained relatively constant across sessions (Fig. 3). Response rate in Food Period II, however, was inversely related to the amount of drug self-administered in the immediately preceding Drug Period (Fig. 3). Thus, when monkeys self-administered an average of about 22 injections of $0.01 \mathrm{mg} / \mathrm{kg} /$ injection, response rate in the subsequent Food Period II was relatively unaffected. Forty injections of $0.03 \mathrm{mg} / \mathrm{kg} /$ injection reduced response rates 
in the subsequent Food Period by about $30 \%$. When the monkeys self-administered an average of 27 injections of $0.1 \mathrm{mg} / \mathrm{kg} /$ injection, responding was typically suppressed in the subsequent Food Period (Fig. 3).

In all monkeys, response rate in DRO $30 \mathrm{sec}$ components remained relatively constant in Food Period I across all self-administration conditions. In Food Period II, the low response rate in DRO $30 \mathrm{sec}$ components usually was affected in the same way as was food-reinforced responding. However, in each monkey, there were a few isolated occasions in which response rates in DRO $30 \mathrm{sec}$ components in Food Period II were increased substantially (2- to 10-fold) above saline control levels. These rate increases were accompanied by reduced rates of food-reinforced responding and were always immediately preceded by relatively high response rates in the Drug Period.

After testing the self-administration doses in an ascending series, the lowest dose at which selfadministration was first initiated was replicated in each monkey. Replication of the initial doses produced results comparable to the first determinations (Fig. 4). Thus, there appeared to be little change in the ratemaintaining effects of DITA over the course of about 3 months of self-administration. In contrast, subsequent replication of a pretreatment with $1.0 \mathrm{mg} / \mathrm{kg}$ (Fig. 2) reflected complete tolerance to the suppression of food-reinforced responding at that dose.

d-Amphetamine Self-Administration. Self-administration of $d$-amphetamine was initiated and maintained at $0.01 \mathrm{mg} / \mathrm{kg} /$ injection in both monkeys tested. $d$-Amphetamine was roughly three times more potent than DITA in maintaining drug-reinforced responding as well as in suppressing food-reinforced responding in Food Period II (Fig. 3). That is, maximal response rate in the Drug Period for $d$-amphetamine was maintained at $0.01 \mathrm{mg} / \mathrm{kg} /$ injection, while maximal response rate for DITA was maintained at $0.03 \mathrm{mg} / \mathrm{kg} /$ injection. In both cases, however, the maximal response rates were comparable. Moreover, the next higher doses of each drug maintained comparable response rates in the Drug Period. The highest dose of each drug decreased response rates to about the same extent in the second Food Period, again demonstrating a roughly three-fold difference in potency. Finally, there was also approximately a three-fold difference in potency in the dose-effect curves for number of injections of each drug (Fig. 3; open symbols). There was little difference between the two monkeys tested in response rates maintained by $d$-amphetamine. This suggests that previous exposure to DITA did not alter the sensitivity to $d$-amphetamine in monkey 628 when compared to the animal (750) exposed only to $d$-amphetamine.

\section{Discussion}

Intravenous pretreatment with DITA reduced the rate of food-reinforced responding under the chain DRO 30 FR30 schedule. As pretreatment dose increased, the suppression of responding was greater in the first Food Period of each session and longer lasting as evidenced by suppression of responding in the second Food Period. The normally low response rates in DRO 30 components generally were only further decreased by DITA pretreatment. These effects are similar to those reported for other amphetaminelike drugs under similar schedule conditions (Woods and Tessel, 1974).

Suppression of food-reinforced performance occurred at doses which did not appear to alter the intake of extraexperimental food. It should be noted, however, that food-reinforced performance was not intended to assess anorexia. Rather, the Food Periods were included so that if DITA failed to function as a reinforcer, we could at least be certain of a behaviorally active dosage range based upon distuption of food-reinforced responding.

Tolerance to response rate decreases developed across successive pretreatments. Moreover, the highest pretreatment dose $(1.0 \mathrm{mg} / \mathrm{kg})$ initially produced nearly complete suppression of responding in the first Food Period and substantially reduced rates in the second Food Period. However, after exposure to DITA selfadministration, the $1.0 \mathrm{mg} / \mathrm{kg}$ pretreatment failed to decrease response rate in either Food Period. In contrast, replications of initial self-administration doses produced results comparable to the original determinations. Similar results have been reported for narcotics under identical experimental conditions (Carney, 1973). These findings suggest that drug effects which result in disruption of responding and, hence, reduction in reinforcement frequency, may show tolerance more rapidly than those which maintain responding (e.g., Schuster et al., 1966).

Self-administration of DITA was initiated and maintained in each of the monkeys. As DITA dose/ injection increased, response rate in the Drug Period increased to a maximum and then decreased. Such dose-effect relationships are typical of drug-reinforced responding under fixed-ratio schedules (e.g., Downs and Woods, 1974). In Food Periods that immediately preceded Drug Periods, response rate was relatively constant across sessions. However, in Food Periods that immediately followed Drug Periods, response rate decreased as DITA self-administration dose increased. For example, response rate in Food Period II was decreased by about one-third when the DITA selfadministration dose was $0.03 \mathrm{mg} / \mathrm{kg} /$ injection despite the fact that maximal response rate was obtained in 
the Drug Period at that dose. It should be noted, however, that the net result of this decrease was to produce equivalent response rates in the Drug Period and in Food Period II. The highest dose, $0.1 \mathrm{mg} / \mathrm{kg} /$ injection, produced even lower response rates in both the Drug Period and Food Period II. These results, then, are consistent with the generalization that drug reinforcers may have concomitant effects which are incompatible with high response rates at high doses (Downs and Woods, 1974; Pickens and Thompson, 1968; Wilson et al., 1971).

DITA was about 3 times less potent than $d$-amphetamine in maintaining rates of drug-reinforced responding as well as in decreasing the rate of subsequent food-reinforced responding. In all other respects, the results with DITA were essentially similar to those for $d$-amphetamine. The fact that the relative potencies for the two drugs in maintaining drugreinforced responding were roughly parallel to their effects on subsequent food-reinforced responding suggests that the present procedure may be useful for examining other amphetamine-like drugs. For example, fenfluramine has been found to be about 10 times less potent than cocaine in decreasing foodreinforced responding, yet fenfluramine fails to maintain drug-reinforced responding over a wide range of doses (Woods and Tessel, 1974). At the very least, procedures which include both drug and nondrug reinforced responding allow for determination of a behaviorally active dosage range. At best, marked dissociation between drug reinforcement and other behavioral effects (e.g., disruption of operant responding) may be predictive of amphetamine-like drugs with minimal abuse potential.

\section{References}

Abdallah, A. H., White, H. D.: Pharmacological evaluation of 3',4'-dichloro-2-(2-imidazolin-2-yl-thio)-, acetophenone hydrobromide (DITA). A new anorexigenic compound. Fed. Proc. 33, 564 (1974)

Carney, J.: Effects of morphine, codeine, and naloxone on food- and codeine-reinforced responding in the rhesus monkey. Fed. Proc. 32, 726 (1973)

Downs, D. A., Woods, J. H.: Codeine- and cocaine-reinforced responding in rhesus monkeys: effects of dose on response rates under a fixed-ratio schedule. J. Pharmacol. exp. Ther. 191, 179-188 (1974)

Pickens, R., Thompson, T.: Cocaine-reinforced behavior in rats: effects of reinforcement magnitude and fixed-ratio size. J. Pharmacol. exp. Ther. 161, 122-129 (1968)

Schuster, C. R., Dockens, W. S., Woods, J. H.: Behavioral variables affecting the development of amphetamine tolerance. Psychopharmacologia (Berl.) 9, 170-182(1966)

Wilson, M. C., Hitomi, M., Schuster, C. R.: Psychomotor stimulant self-administration as a function of dosage per injection in the rhesus monkey. Psychopharmacologia (Berl.) 22, 271-278 (1971)

Woods, J. H., Tessel, R. E.: Fenfluramine: amphetamine congener that fails to maintain drug-taking behavior in the rhesus monkey. Science 185, $1067-1069$ (1974)

Dr. David A. Downs, Department of Pharmacology, M 6322 Medical Science 1

University of Michigan Medical School, Ann Arbor, Mi. 48104, U.S.A. 